\title{
Integrated Scenarios of Regional Development in Two Semi-Arid States of North-Eastern Brazil
}

\author{
PETRA DÖLL ${ }^{1}$ AND MAARTEN S. KROL ${ }^{2}$ \\ ${ }^{1}$ Center for Environmental Systems Research, University of Kassel, Kassel, Germany, and ${ }^{2}$ Potsdam Institute for \\ Climate Impact Research, Potsdam, Germany
}

\begin{abstract}
Scenario analysis of the future is an important tool for supporting sustainability-oriented regional planning. To assist regional planning in two federal states in semi-arid North-eastern Brazil, Ceará and Piauí, we developed integrated qualitative-quantitative scenarios that show potential developments of the agricultural and water resources situation as well as the internal migration until the year 2025. In these states, regional development is negatively influenced by the high seasonality of rainfall and El-Niño-related drought years. Two reference scenarios, "Coastal Boom and Cash Crops" and "Decentralisation - Integrated Rural Development," were developed. First, story lines were created and the development of the driving forces was quantified. Then, an integrated model, which includes modules for simulating water availability, water demand, and agricultural production and income, was applied to compute the temporal development of relevant system indicators in each of the 332 municipalities of Ceará and Piauí. These indicators encompass the fraction of the irrigation water demand than can be satisfied, the volume of water which is stored in the reservoirs at the beginning of the dry season, agricultural productivity and production as well as the internal migration among scenario regions. In addition, the impact of certain policy measures was assessed in the context of both reference scenarios. Reference and intervention scenarios were derived by an interdisciplinary group of scientists and were discussed and refined during policy workshops with planning agencies of Ceará.
\end{abstract}

Keywords: scenario, regional planning, integrated model, migration, water availability, water demand, reservoir, agricultural production.

\section{INTRODUCTION}

North-eastern Brazil, where one third of the Brazilian population lives, is the poorest region of the country. The 1996 per capita Gross Domestic Product (GDP) in the state of Ceará, for example, was below half of the average value for Brazil of 4800 1996-US\$, while in the state of Piauí, it was below one third. For more than a century, many people have emigrated from the Northeast, mostly to the more affluent South of Brazil or to the Amazon region. Scarcity of water is a major constraint for development in North-eastern Brazil, which suffers from a strong seasonality of rainfall as well as from recurrent drought years, partly related to the El Niño phenomenon. Water scarcity affects both agricultural production and water supply. While more than $40 \%$ of the labour force of Ceará and Piauí works in agriculture, about $70 \%$ of the farmers can be considered to be subsistence farmers, which are particularly vulnerable to drought. Less than $1 \%$ of the agricultural area is irrigated, and even though water is scarce, an extension of irrigation is considered to improve the security of farmers as well as their income.
With respect to water supply, the situation in Ceará is difficult due to the mostly crystalline bedrock with little exploitable and often saline groundwater. In the dry season from June to December, water is only available due to the 8,000 very small to large reservoirs, but in dry years they are often empty. In Piauí, there are extensive sedimentary aquifers that can be used for water supply but due to the low groundwater recharge rate, their exploitation is prone to become unsustainable. In the El Niño drought year 1998, for example, the situation of rural population became so desperate that shops were looted. Many reservoirs fell dry such that in some towns tap water was no longer available.

In Brazil, it is generally recognised that regional planning should be aimed at achieving a sustainable development. Scenario analysis is an important tool for regional planning that is oriented at sustainable development. Many of today's decisions and activities will have a significant impact in the quite distant future. If sustainable development is to be achieved, it is necessary to assess impacts. An example is the decision in favour of building a reservoir that it likely to still 


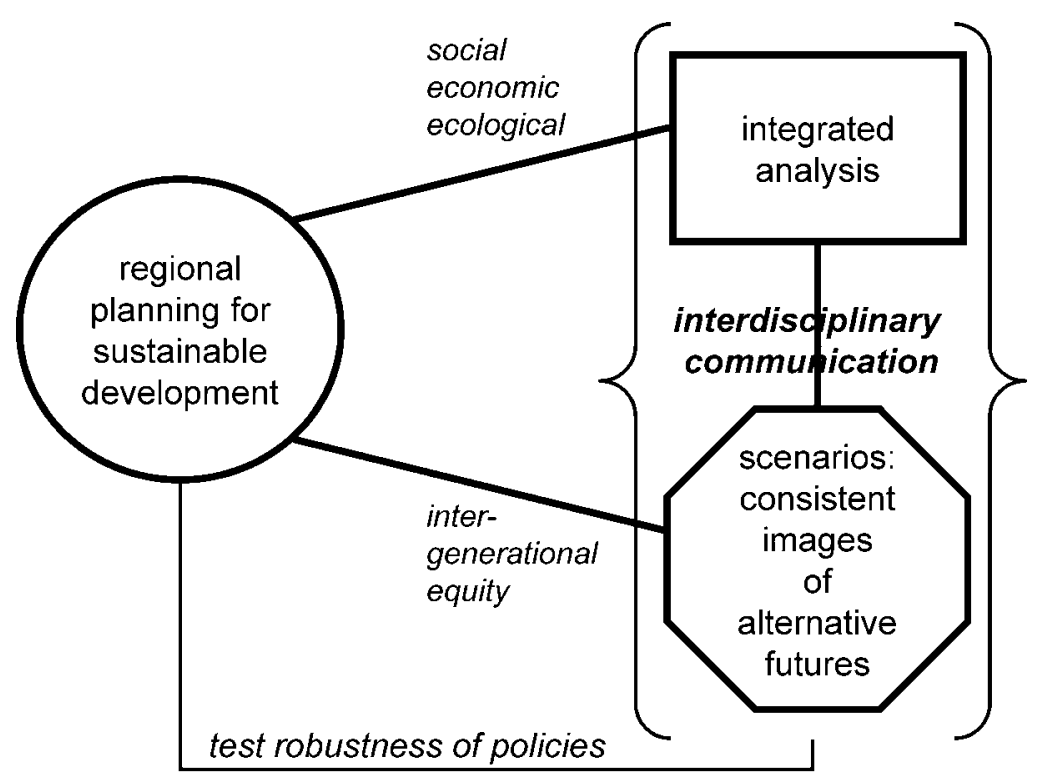

Fig. 1. Relationship between regional planning for sustainable development, integrated analysis and scenarios.

exist more than 100 years after its construction. The construction of scenarios helps to see how the uncertain future might unfold [1] and how the future might be influenced by today's decisions. In our understanding, scenarios are consistent and plausible images of alternative futures.

Figure 1 illustrates how regional planning for sustainable development is related to integrated systems analysis and scenario development. On the one hand, the goal of sustainable development requires a regional planning in which policy measures and projects are not only assessed with respect to financial and technological feasibility, but with respect to - ideally - all technological, ecological, economic and social aspects. Thus, an integrated analysis of the system of interest is needed. On the other hand, regional planning that takes into account inter-generational equity, a core idea of sustainable development, needs to consider the long-term future and is thus supported by the construction of scenarios.

Scenarios show different possibilities of how the future might look like. A scenario neither predicts the future nor should it be qualified by a probability. Scenarios should be just images of possible futures that are rich enough to help decision making. Preferably, they do not represent the situation at a certain point in future but the dynamic development of the system. Regional scenarios also show the consequences of larger-scale (global, continental, national) developments for the region. Scenarios are always integrated to some extent, as it is not possible to derive images or stories of the future that do not include demographic, economic and technological aspects. Thus, an integrated systems analysis can support the scenario development. Obviously, the planning or research aim and scope will determine which parts of the image, especially which aspects and processes, are refined and which are only considered in a coarse manner.

The robustness of a certain policy can be tested by assessing its impact in different possible future situations (Fig. 1). Thus, scenarios can help to demonstrate what impact regional planning might have. Both integrated systems analysis and scenario development require, and thereby encourage, interdisciplinary communication [2].

To support sustainability-oriented regional planning in Piauí and Ceará, the German-Brazilian co-operation programme WAVES (http://www.usf.uni-kassel.de/WAVES) focussed on the interrelation between climate variability, water availability, agriculture and migration. Integrated qualitative-quantitative scenarios of regional development in Ceará and Piauí were developed by a multidisciplinary scenario group, which experienced that scenario development is a means for integration and interdisciplinary communication. Various numerical models were developed, covering the total area of both states, including a hydrological model, a water use model, an agricultural yield model, an agro-economic model, and a migration model. The models were coupled to form an integrated model that was applied to quantify the integrated scenarios. In order to improve the relevance of the developed scenarios for regional planning, the scenarios were discussed and refined during three policy workshops with planning agencies of Ceará. In these workshops, the plausibility of the scenario assumptions was discussed and interesting policy measures (interventions) were defined.

This paper is organised as follows. In the next section, the methodology to derive qualitative-quantitative scenarios is described. In Section 3, the two reference scenarios that were developed within the WAVES programme are presented, including the story lines, the quantification of the 
driving forces and the modelled system indicators. The impact of selected policy measures is assessed in Section 4. In Section 5, conclusions are drawn with respect to regional planning in Ceará and Piauí as well as with respect to scenario development in general.

\section{METHODOLOGY}

Scenarios can be qualitative (pure narratives of alternative futures), quantitative (only numerical output), or a combination of both. In two recent global scenario development efforts, global greenhouse gas emissions scenarios of the Intergovernmental Panel on Climate Change [1] and the World Water Vision scenarios [3], qualitative-quantitative approaches were taken. In WAVES, we adapted these approaches and derived qualitative-quantitative scenarios in which qualitative knowledge and ideas are combined with quantitative mathematical modelling.

Reference scenarios describe futures without any specific policy measures. They serve as the baselines to assess the impact of additional policy measures on the future state of the system (intervention scenarios). While reference scenarios might implicitly include some policy measures related to the topic of interest, e.g., water use, these policy measures continue certain existing policy trends, while the interventions are possible new policies. It is recommended to produce two or four reference scenarios with quite distinct story lines, avoiding one scenario to be considered as the "most probable," while the others are not given full consideration [4].

The methodology to derive qualitative-quantitative scenarios encompasses the following steps:

1. Identification of problem field.

2. System definition including driving forces, temporal and spatial resolution and extent (base year, time horizon and time step, scenario regions).

3. Definition of indicators of the system state (related to the mathematical models, available to compute indicators).

4. Development of qualitative reference scenarios as story lines (narrative descriptions of alternative futures).

5. Development of quantitative reference scenarios:

(a) Quantification of the driving forces.

(b) Computation of the indicators using mathematical models.

6. Development of intervention scenarios:

(a) Identification of interesting interventions.

(b) Modification of selected driving forces or parameters of reference scenarios.

(c) Computation of the indicators using mathematical models.

7. Evaluation of the scenarios.
Ideally, scenarios are derived by an interdisciplinary group of scientists, policy makers and stakeholders. In the WAVES program, policy makers and stakeholders participated in particular in Steps 3, 4, 6a, and 7.

Scenario development is an iterative process, and it is desirable to discuss preliminary scenarios available after Step 5 has been performed for the first time, preferably among scientists, decision makers and stakeholders, and then to revise story lines and quantifications. In a regional planning process, Steps 3 to 7 are likely to be repeated. After a first computation and evaluation of the system indicators, in particular the indicator definition can be refined, and new interventions might become interesting.

In this paper, we focus on the core of scenario development, Steps 4 to 6 . After developing the scenario storylines (Step 4), driving forces and indicators of the reference scenarios are quantified (Step 5). Here, we define driving forces as those variables that cannot be computed by the applied models but are needed as model input. Both the quantified driving forces and the computed model variables (indicators) are part of the quantitative scenario. In order to make assumptions about the future development of certain driving forces, their historical development is first analysed. Then, numerical values of the driving forces that reflect the respective qualitative scenario are defined for future times. Care must be taken to achieve consistency in quantifying driving forces that are known to be correlated or have a scale-caused one-way dependency. For example, driving forces like climate or food prices are globally defined, affecting smaller spatial units like federal states, but can barely be influenced by any actions at that smaller scale. When all input necessary for the various models is quantified, the models can be used to compute the system indicators for the various reference scenarios. Intervention scenarios are defined by modifying one or more driving forces or parameters of the reference scenarios (Step 6). In general, to test the robustness of the intervention, the impact of an intervention is assessed against the backdrop of all reference scenarios.

It is important to note that the study area is generally subdivided into homogeneous spatial subunits, the scenario regions, for which the story lines and the quantitative assumptions of the development of the driving forces are developed (Step 2). The scenario regions are usually larger than the spatial subunits of the mathematical models used to compute the systems indicators.

\section{REFERENCE SCENARIOS OF REGIONAL DEVELOPMENT}

In the WAVES programme, qualitative-quantitative scenarios of the situation in Ceará and Piauí up to the year 2025 were developed (base year 1996/98). Two reference scenarios and a larger number of intervention scenarios 


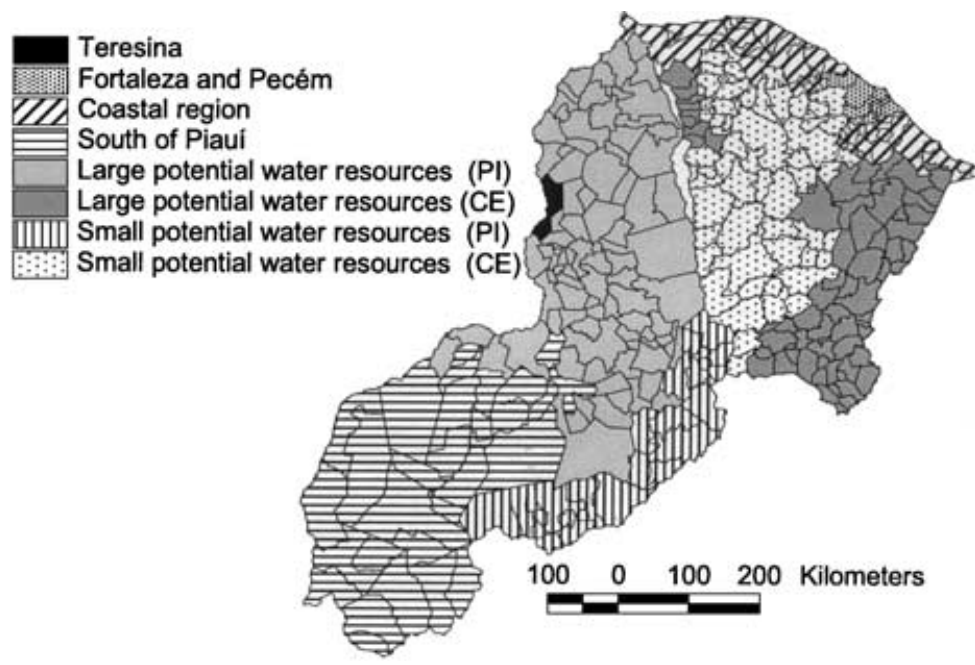

Fig. 2. The eight scenario regions, the spatial units for developing story lines and quantitative assumptions about the development of driving forces. The white areas between Piauí and Ceará are disputed between both states and hardly inhabited. The smallest units denote municipalities, for which system indicators are computed.

were devised. Reference scenario A (RS A) is called "Coastal Boom and Cash Crops," reference scenario B (RS B) "Decentralisation - Integrated Rural Development." For scenario development, the study area was subdivided into eight scenario regions (Fig. 2), which are assumed to differ with respect to the future development of the driving forces. Criteria for the configuration of the scenario regions were the similarity in agro-economic and natural conditions (precipitation, position within river basin, sedimentary, and crystalline sub-surface) and administrative boundaries.

\subsection{Story Lines}

For each of the two reference scenarios, a story line was written, covering aspects that are important with respect to rural development and to the water scarcity problems in the study area. Table 1 provides a concise characterisation of RS $\mathrm{A}$ and RS B. Each reference scenario continues certain existing trends. RS A ("Coastal Boom and Cash Crops") carries on the current trend of increased cash crop production for the Brazilian and external market, the efforts to promote tourism mainly along the coast and the fast economic development in the growing metropolitan area of Fortaleza, the capital of Ceará. RS B ("Decentralisation - Integrated Rural Development") takes up the strengthening of regional centres, for example by the establishment of universities, which has recently begun in the study area.

As regional development is strongly influenced by global development, the two reference scenarios were designed such that they can be embedded into global scenarios. For the Third Assessment Report of the Intergovernmental Panel on Climate Change (IPCC), four global scenario families were developed [1]. A comparison of the story lines of the global scenarios to those of our regional scenarios shows that RS A can be embedded in global IPCC scenario family A1 and RS B in scenario family B2 (Fig. 3).

The A1 story line describes a future world of very fast economic growth and the rapid introduction of new and

Table 1. Characteristics of the two reference scenarios.

Reference scenario A (RS A) "Coastal Boom and Cash Crops"

- strong economic development (commerce, industry, tourism) in the coastal regions of Piauí* and Ceará

- Fortaleza grows very fast

- wherever water is available for irrigation, production of cash crops by large companies dominates over subsistence farming

- Brazilian and global markets for agricultural products dominate

- centralised governance prevails
Reference scenario B (RS B) "Decentralisation - Integrated Rural Development"

- regional centres prosper (attractive mediumsised towns with improved infrastructure)

- regional centres have become the markets for local and regional agricultural products

- small-scale agro-industry has extended

- local initiatives prevail

- Piauí and Ceará show a high degree of autonomy in relation to the Brazilian South

- international agencies support sustainable agriculture in crisis-prone regions 


\begin{tabular}{|c|c|c|}
\hline & $\begin{array}{l}\text { oriented mainly towards } \\
\text { economic growth }\end{array}$ & $\begin{array}{l}\text { oriented mainly towards the } \\
\text { environment and social innovation }\end{array}$ \\
\hline \multirow{2}{*}{$\begin{array}{l}\text { globalised world } \\
\text { regionalised world }\end{array}$} & global A1/regional RS A & global B1/none \\
\hline & global A2 / none & global B2 / regional RS B \\
\hline
\end{tabular}

Fig. 3. Correspondence of regional reference scenarios for Piauí and Ceará with the global IPCC scenario families [1].

more efficient technologies. A strong globalisation with intensive economic and cultural exchanges leads to a convergence of wealth and lifestyle among the world regions. In such a world, the strong economic development in the coastal region and the cash crop production in regions with enough water for irrigation that is assumed in the regional reference scenario RS A is plausible. The globally strong economic development results in buyers for industrial and agricultural products, increased investments of foreign companies and an increasing number of tourists from countries that do not yet participate in global tourism.

The B2 story line describes a world in which the emphasis is on local solutions to economic, social, and environmental sustainability. The B2 world of 2025 is less globalised than the A1 world but still more globalised than today's. It is a world with intermediate levels of economic development, less rapid and more diverse technological change than in the A1 story line, and with strong social innovation. In such a world, we can imagine Piauí and Ceará as described in the integrated rural development scenario RS B. Local markets become more important, while global (and Brazilian) markets are rather weak. Without an economic boom and intensive cash crop production, it might be easier to achieve environmental sustainability. Finally, the diversification of production in agriculture and (small-scale) agro-industry requires social and economic innovations.

\subsection{Quantification of Driving Forces}

The mathematical models applied for the quantification of scenarios require many input variables, i.e., driving forces to be quantified beforehand for each of the eight scenario regions. Driving forces of overall importance were quantified first (population, gross domestic product GDP, irrigated area etc.). Afterwards the remaining driving forces were quantified in accordance with the main driving forces and the story lines. Here, we only present the quantification of population, per-capita GDP, irrigated areas, reservoir construction and climate change. This selection provides information on the most important driving forces of the system of interest, taking into account the focus on water and land use management. Other driving forces are described in Krol et al. [5], Döll and Hauschild [6], and Höynck [7]. For most driving forces, the differences between scenarios RS A and RS B only emerge gradually, and further divergence after 2025 is envisioned.

\subsubsection{Population}

Population development drives migration, water use and agro-economy. For RS A and RS B, two different population scenarios were derived. They differ with respect to the distribution of population among scenario regions (Table 2) but total population growth in the study area is assumed to be the same in both scenarios. In RS $A$, the fraction of the population living along the coast and in the two capitals increases strongly, while in RS B, the current trend of migration from the hinterland to the coast weakens. It is assumed that fertility and mortality continue to decrease in the future following historic trends, and that the more recent trend of decreasing net migration continues. By 2025, both the fertility rate and the net migration will have dropped to approximately $65 \%$ of the 1996 value, and the mortality rate to approximately $85 \%$. According to the population model, the number of inhabitants of the study area increases from 9.5 million inhabitants in 1996 to 11.9 million in 2025 [6].

\subsubsection{Gross Domestic Product}

Like population scenarios, GDP scenarios influence migration, water use and the agro-economy. Per-capita GDP in the

Table 2. Spatial distribution of population: Historical data and scenarios.

\begin{tabular}{|c|c|c|c|c|}
\hline \multirow[t]{2}{*}{ Scenario region } & \multicolumn{4}{|c|}{$\begin{array}{c}\text { Fraction of total population of Ceará and Piauí in } \\
\text { each scenario region [\%] }\end{array}$} \\
\hline & 1991 & 1996 & 2025 RS A & 2025 RS B \\
\hline Teresina & 6.7 & 6.9 & 8.1 & 7.3 \\
\hline Metropolitan area of Fortaleza and Pecem & 26.1 & 27.6 & 35.4 & 30.6 \\
\hline Coastal region & 12.7 & 12.8 & 17.4 & 13.3 \\
\hline Southern part of Piauí & 3.1 & 2.9 & 2.4 & 2.9 \\
\hline Regions with large potential water resources (PI) & 14.5 & 13.9 & 11.4 & 13.5 \\
\hline Regions with large potential water resources (CE) & 19.4 & 19.0 & 15.5 & 18.4 \\
\hline Regions with small potential water resources (PI) & 2.9 & 2.7 & 1.6 & 2.3 \\
\hline Regions with small potential water resources (CE) & 14.7 & 14.1 & 8.2 & 11.7 \\
\hline
\end{tabular}


study area is approximately one half of the Brazilian average, and the average growth rate since 1970 has been somewhat higher than the Brazilian one. The global IPCC scenario A1 (to which RS A fits) shows a higher growth rate of per-capita GDP than the global scenario B2 (RS B) [1], approximately $4.5 \% / \mathrm{yr}$ in $\mathrm{A} 1$ and $2.4 \%$ in B2. In particular in the case of $\mathrm{A} 1$, growth is much higher than the average historical growth rates from 1950 to 1990 for Brazil and Latin America, which for the decade 1980 to $1990 \mathrm{had}$ even negative growth rates. Besides, the Decentralisation Integrated Rural Development scenario RS B shows an economic development that results in rather similar economic growth rates as the Coastal Boom and Cash Crops scenario RS A for the study region as a whole, but with a different regional distribution. Therefore, we assume a percapita GDP increase of 2.7\%/yr from 1996 to 2025 in RS A (except for Teresina and the regions with small potential water resources, with $2.5 \% / \mathrm{yr}$ ), and $2.2 \% / \mathrm{yr}$ in $\mathrm{RS} \mathrm{B}$ (except for regions with large potential water resources, with $2.4 \% / \mathrm{yr})$.

\subsubsection{Irrigated Areas}

Irrigated areas have a very strong impact on water use and thus water scarcity as well as on the agro-economy of a region. In Brazil, irrigated areas were extended by $7 \% / \mathrm{yr}$ in the $1970 \mathrm{~s}$, by $5 \% / \mathrm{yr}$ in the $1980 \mathrm{~s}$ but by only $1.2 \% / \mathrm{yr}$ between 1990 and 1998 [8]. Here, and in the following, the term "irrigated areas" refers to the areas that are equipped for irrigation. This decreasing trend is observed in most countries and is due to restricted water and land resources. In Ceará and Piauí, however, rural development is still considered to be strongly linked to irrigated agriculture. Therefore, large increases of irrigated area are foreseen in both reference scenarios, with an average over the study area of $3.8 \% / \mathrm{yr}$ in $\mathrm{RS} \mathrm{A}$ and $2.5 \% / \mathrm{yr}$ in $\mathrm{RS} \mathrm{B}$. For RS A, all public irrigation projects planned in 1998 according to Lopes Neto [9] are assumed to be implemented, while private irrigation, which accounts for approximately half of the current irrigated areas, increases by $2 \% / \mathrm{yr}$ from $1996 / 98$ to 2025 . The $2 \%$ increase represents the average for the study area Piauí and Ceará and differs among the scenario regions. These assumptions lead to an increase of irrigated areas in the study area from 56,000 ha in 1996/98 to 161,000 ha in 2025 , with 84,000 ha in new public projects and 21,000 as new private irrigation. For RS B, with its decentralised development based on small-scale local initiatives, it is assumed that only a fourth of the area in each of the planned public irrigation projects is implemented up to 2025 , but that private irrigated areas increase by $2.9 \% / y$. Irrigated area in 2025 , for RS B, is 112,000 ha (new projects: 21,000 ha, new private irrigation: 35,000 ha). In both scenarios, the additional private irrigated areas of a scenario region is distributed among the municipalities according to the following rule: $50 \%$ of the additional areas is distributed homogeneously over all municipalities, and $50 \%$ in proportion to the $1996 / 98$ irrigated area.

\subsubsection{Reservoir Construction}

In particular in Ceará, where groundwater resources are very small, reservoirs are the main source of water supply. Over the last 100 years, the construction of reservoirs has been one of the main strategies to extend the availability of surface water into the dry season or into coming drier years, and to perennise rivers. The largest number and total capacity (not considering the Represa Sobradinho in Bahia) of reservoirs in North-eastern Brazil is found in Ceará. There, the large storage capacity installed already limits the possibilities to further increase water availability by this strategy. In the case of Piauí, we do not take into account the construction of new reservoirs. In the case of Ceará we assume, for both reference scenarios, that the Castanhão dam in the Jaguaribe basin will be finalised in 2001 (storage capacity $4450 \cdot 10^{6} \mathrm{~m}^{3}$ ). The investments for additional reservoirs will continue at the present rate $(8$ mio $\mathrm{R} \$ / \mathrm{yr})$ until 2025 , which results in a total of 51 reservoirs with $3150 \cdot 10^{6} \mathrm{~m}^{3}$ of additional storage capacity in Ceará. The sequence of reservoirs follows a prioritisation list of the State of Ceará (PROGERIRH), but in RS A investments are more concentrated in the coastal zone.

\subsubsection{Climate Change}

Climate change scenarios for the years 2000-2050 were derived by a statistical downscaling method, taking into account precipitation change in North-eastern Brazil as computed by global climate models for a $1 \%$ yearly increase of greenhouse gas concentrations, and historic station data for 1921-1980 [10]. In the scenarios presented in this paper, only results from the ECHAM4 climate model of the MaxPlank-Institute, Hamburg, Germany were used. ECHAM4 is one of the few global climate models with a realistic representation of the climate in North-eastern Brazil during the 20th century. The computed average precipitation over the study area of the period 2011-2040 is $864 \mathrm{~mm} / \mathrm{yr}$, compared to $875 \mathrm{~mm} / \mathrm{yr}$ for 1939-1968 and $905 \mathrm{~mm} / \mathrm{yr}$ for 1969-1998. Climate variability dominates climate change in the simulation period until 2025. For an assessment of different GCM-projections of regional climate until 2050, and regional impacts, see Krol et al. [5].

\subsection{Model-Based Quantification of Indicators}

Within WAVES, a number of disciplinary models (climate, water availability, water use, agricultural productivity, agroeconomy/land use, and migration) were developed for both the state level (spatial resolution: municipalities; spatial extent: Ceará and Piauí) and the focus region level, and were coupled to form two integrated models. All these models can be used to quantify the indicators of the scenarios. Quantification of scenarios using integrated models provides a 
support for the consistency of the scenarios. In addition, integrated models simulate not only causal chains, but also feedback effects, for example the effects of water use on water availability. In the following, we focus on a few integrating indicators that are derived by the large-scale integrated model SIM [5] for the 332 municipalities of Ceará and Piauí:

- water scarcity, based on water demand and supply, and represented by a water supply sufficiency index for irrigation,

- agricultural production, based, as an example, on maize yields and tomato production, and represented by farm income and

- migration.

\subsubsection{Water Scarcity}

Alleviating water scarcity is one of the major policy goals in North-eastern Brazil, making the assessment of water scarcity a central objective in the present scenario analysis. In principle, water scarcity is a function of water supply and water demand. Water scarcity is the most direct impact of drought conditions or overuse of the natural resources. In both reference scenarios, withdrawal water demand increases strongly until 2025 (Fig. 4), by approximately $110 \%$ in the case of RS A, and $60 \%$ in the case of RS B. Almost $90 \%$ of these increases are due to the assumed extension of irrigated agriculture, while increased water demands in the domestic, industrial, tourism and livestock sectors may be regionally important but overall are less relevant [6]. Water demand for irrigation shows a strong inter-annual variability as it is negatively correlated with precipitation volumes. The increase in water extraction (volume of water that can actually be withdrawn to fulfil the demand) is smaller than that of water demand, as water supply does not meet demand, especially for increased irrigation (see below).

Even though the total renewable water resources (annual surface runoff and groundwater recharge, modelled as described in Güntner and Bronstert [11]) will not change appreciably until 2025, water supply does, due to the construction of new reservoirs, adding to surface storage

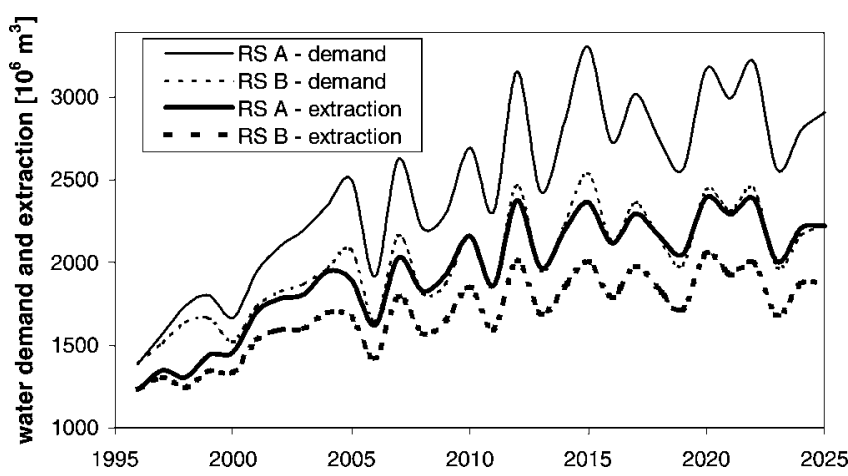

Fig. 4. Total annual water demand and water extraction in Ceará and Piauí.

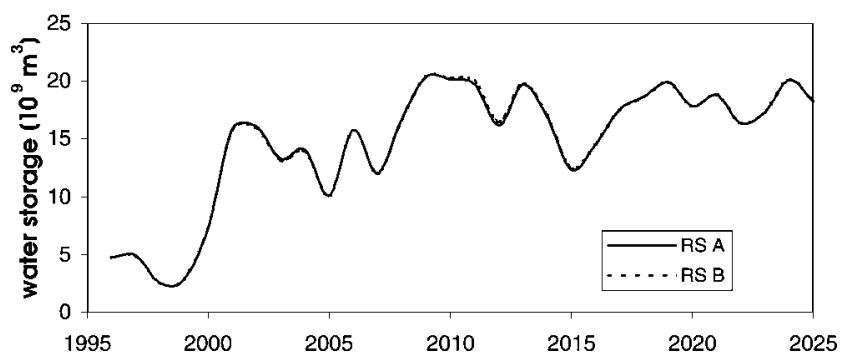

Fig. 5. Water storage in large reservoirs, at the beginning of the dry season (1st of July).

capacity. Potential water supply can be partially represented by the total volume of water that is stored in large reservoirs at the beginning of the dry season. This value is mainly determined by water storage infrastructure and climatic conditions, with small differences between the two scenarios (Fig. 5). The water volume stored is generally very large, but a large part is not for water supply. For example, the Boa Esperança reservoir (Parnaíba basin) at the western border of Piauí, with a capacity of $5000 \cdot 10^{6} \mathrm{~m}^{3}$, is used for hydropower generation. The increase in the year 2001 is due to the newly constructed Castanhão dam.

The net effect of the increasing trends of both water demand and supply on water scarcity depends critically on the spatial distribution of water availability and water demand. To quantify the scarcity, a water sufficiency index was calculated, evaluating which part of demand can actually be covered by the availability. This indicator is computed for each of the water use sectors irrigation, livestock, households, industry and tourism, which differ with respect to their sources of water (groundwater, surface water). In case of water scarcity, the irrigation sector will only be provided by the water volume that is not needed by the other four sectors, which is according to the legal requirements in the study region. Figure 6 shows the temporal development of water supply sufficiency for the irrigation sector, where a value of 1 indicates a complete coverage of demand (no scarcity impact). The irrigation sector is selected here because it is the dominant use sector, and because it mainly depends on surface water. There is a

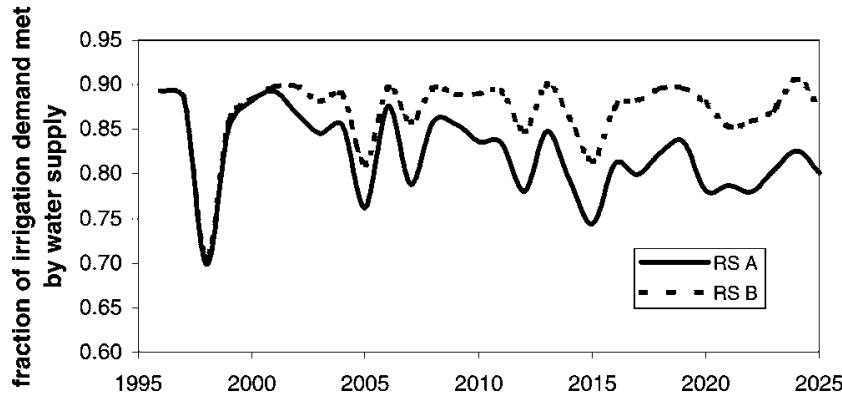

Fig. 6. Water supply sufficiency for irrigation: fraction of the water demand for irrigation that can be covered by water supply. 
gradual downward trend in water sufficiency for RS A from $88 \%$ down to $80 \%$, whereas for RS B the value remains at $88 \%$. The decreasing water sufficiency in the case of RS A is fully attributable to negative tendencies in the regions with large potential water resources and the coastal zone. This indicates that in these regions, water scarcity is increasing with time, and the additional water demands from expansion of the irrigated area cannot be met. In the case of RS B, the expansion in irrigated area in all regions is better adapted to the available and increased water supply.

In the scenario assumptions of RS A and RS B, precipitation reduces by $7 \%$ until 2025 , but the effects of climate change until 2025 are small compared to the effects of increasing demands and the expansion of supply systems.

\subsubsection{Agricultural Production}

Agricultural production is strongly affected by climate, but also by the possibilities for irrigation. Both rain-fed and irrigated production depend on precipitation. Rain-fed production is directly affected by negative anomalies in precipitation, especially when the rainy season is significantly shortened or when longer dry spells within the rainy season occur, depleting soil moisture. Irrigated production is affected by unfavourable climatic conditions in two ways. Firstly, water supply for irrigation is less in drier years, especially after a sequence of drier years. Secondly, irrigation water demand is higher.

Rain-fed yields strongly depend on climate, and the differences between RS A and RS B play a negligible role (only through the way in which they impact on the spatial distribution of cropping areas). Until 2025, climate change shows little influence on the yield of, for example, maize (Fig. 7): both mean yield and variability do not exhibit a significant trend.

For the irrigated production of, for example, tomato, clear trends and differences between the two scenarios appear, which are due to a higher increase of irrigated tomato production in RS A (Fig. 8). In RS A, production increases by $340 \%$, in RS B by $220 \%$, even though in RS A, a larger part of the area equipped for irrigation cannot be irrigated due to lack of water (Fig. 6).

For almost all crops, production increases are found in both reference scenarios, except for cassava, mostly

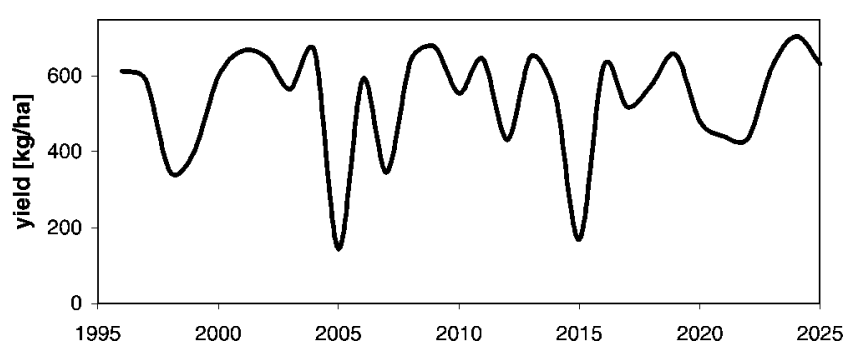

Fig. 7. Temporal development of mean rain-fed maize yield in both reference scenarios.

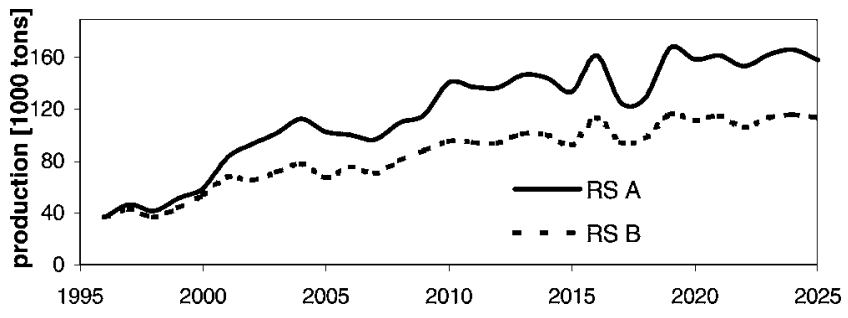

Fig. 8. Tomato production in Ceará and Piauí in RS A and B.

cultivated on smaller farms, whose areas are decreasing. For crops that are mostly grown under rain-fed conditions, production increases are very similar for the RS A and RS B scenario; for crops with relevant share of irrigated production, production increases in RS A are stronger, due to the faster expansion of irrigated areas.

As a result, total farm income grows faster in RS A than in RS B. It is distributed spatially uneven in both scenarios, and is somewhat more pronounced in RS A. The inter-annual variability of agricultural GDP remains very large, with negative net values for the 3 driest years until 2025. Due to the large variability, a statistically significant growth trend cannot be identified. The difference between RS A and RS B, however, shows an increasing trend, which is due to the different proportions of high-value irrigated crops. The difference reaches approximately half of the mean agricultural GDP of the 1990s but results are very uncertain, as the assumed costs and prices are uncertain; in particular the profitability of smaller farms is uncertain [7].

\subsubsection{Migration}

Migration is one of the most noticed societal impacts of adverse natural conditions in North-eastern Brazil. Scenarios of migration are to be interpreted with caution. Migration is simulated to be mainly driven by gradients in income, mimicking large scale migration within the states of Ceará and Piauí and outside of these states over longer periods [12]. This makes GDP (total and agricultural) and its growth rates the main drivers of migration, but the income drop in drought years, enhancing the rural-metropolitan income gradient, as the direct incentive for migration. Model simulations successfully reproduce the assumed tendencies in population development and its regional distribution. Considering net migration from the Sertão (scenario regions with large and small potential water resources - Fig. 2), the dynamical feature of high migration in drought years remains due to the continued variability of agricultural GDP (Fig. 9), with persistently lower numbers for RS B (total migration is $25 \%$ higher in RS A). The lower migration in RS B is mainly due to the more uniformly distributed agricultural income. Unfortunately, there are no historic data of migration from the Sertão nor annual values of migration from the whole study area that could be used to check the plausibility of the computed migration; the annual net migration from the study area averaged over the period 


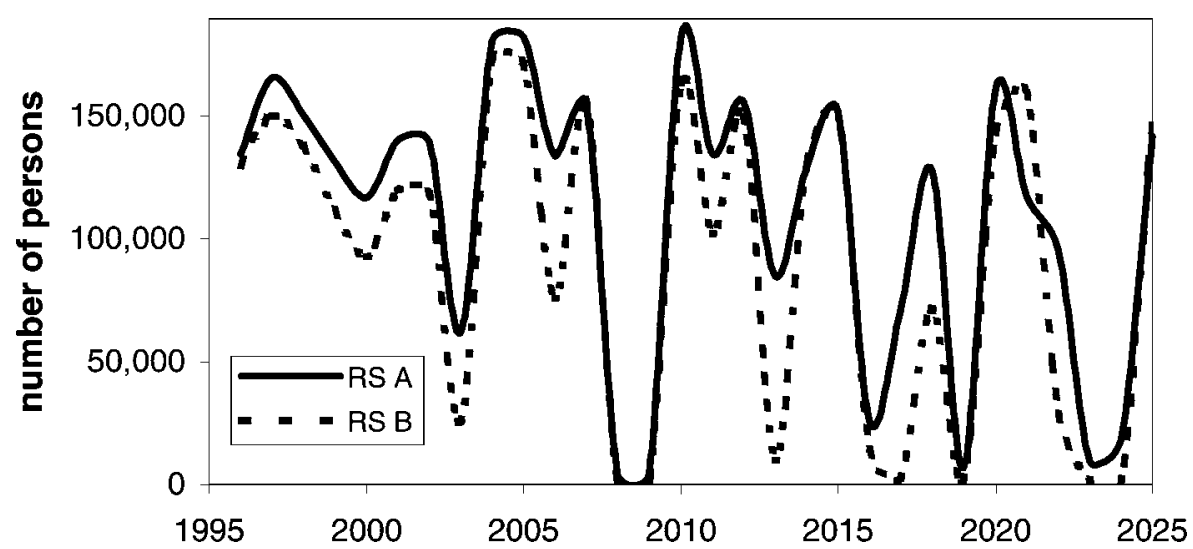

Fig. 9. Annual net migration from the Sertão.

1991-1996 was 60,000 . In the migration simulation, the effect of emergency measures, which support the rural population in drought years, is not taken into account explicitly, such that migration peaks are likely to be highly overestimated. In summary, the present (incomplete) quantitative understanding of migration indicates that there will be no consistent decrease in migration from the Sertão, even under the assumption of economic growth in the Sertão.

\section{INTERVENTION SCENARIOS}

In an exemplary manner, the impact of three different policies or management measures is analysed against the backdrop of the two reference scenarios: water pricing, reduced reservoir construction, and introduction of highyield cashew varieties.

\subsection{Water Pricing}

Appropriate pricing of water helps (1) to achieve the economically most efficient use of water, (2) to avoid its wasteful use and thus to protect the environment and (3) to generate financial resources to improve water supply and water management. In the regional water use model NoWUM, water use in households connected to the public water supply and water use by industry is simulated to be influenced by the water price due to the price elasticity of water use [6]. With a price elasticity of -0.5 , for example, water use decreases by $5 \%$ if water price increases by $10 \%$. Price elasticity in the domestic sector is lower than in the industrial sector. While in the domestic sector, publicsupplied and self-supplied households are distinguished (the latter not being affected by water pricing), this distinction cannot be made in the industrial sector due to lack of data; this is likely to lead to an overestimation of the responsiveness of industrial water use to water pricing by the public water suppliers. Unfortunately, there is a lack of reliably data on price elasticities in Brazil, which leads to significant uncertainties in the computed impact of water price on water use. Besides, it is at present not possible to apply the price elasticity concept for irrigation water use as there is no knowledge about price elasticities in this water use sector.

In general, the current water prices in Piauí and Ceará only cover operation and maintenance costs, but not investment costs, for example for an extension of water supply, or environmental costs. However, it is widely recognised that sustainable development requires a full-cost pricing for water services [3, p. 2]. Currently, approximately $1 \%$ of the average per-capita GDP in the study area is spent for (public) water supply, which is comparable to the situation in Germany, with a tenfold per-capita GDP and approximately the same per-capita water use. The increase assumed for both reference scenarios (6\%/yr) from 1996/98 to 2025 (compare section 3.2) is smaller than the historic price increases in Ceará during the last decade (which was 8-11\%/yr, based on 1989-1998 data from CAGECE, the main water provider in Ceará). A price increase of only $2.5 \% / \mathrm{yr}$ results in an approximately constant fraction of the total income that is spent on water, and it is unlikely that with such a price development, investment costs could be covered. A price increase of $11 \% / \mathrm{yr}$ (the price increase of the fixed fee component of the water tariff in Ceará during the last decade) leads, on average, to a water price that, with the same per-capita water use, amounts to about $10 \%$ of the per-capita GDP. Given the very strong income discrepancies in the study region, such a high water price might be socially unacceptable. Please note that the prices per volume of freshwater will effectively double when households get connected to the sewage system (in 1996/98, only about $10 \%$ of the urban withdrawals are discharged into a sewage system).

With an $11 \% / \mathrm{yr}$ increase of water price, total domestic water use (including self-supply) decreases by approximately $45 \%$ as compared to the reference scenarios (where $6 \% / \mathrm{yr}$ was assumed), while with $2.5 \% / \mathrm{yr}$, it increases by about $40 \%$. The impact of different water pricing is approximately the same in both reference scenarios. By 
2025, industrial water use intensity (withdrawal water use divided by industrial GDP) will have decreased to $16 \%$, $37 \%$, and $66 \%$ of the present value in the cases of $11 \%, 6 \%$, and $2.5 \%$ water price increase per year, respectively. Consequently, industrial water use in the study area decreases by $58 \%$ in the case of $11 \% / \mathrm{yr}$, and increases by $80 \%$ in the case of $2.5 \% / \mathrm{yr}$ as compared to the reference scenarios.

\subsection{Reduced Reservoir Construction}

To assess the beneficial effects of the reservoirs that are assumed to be constructed until 2025 in the reference scenarios, variants of the scenarios were defined in which less dams are constructed. While in both RS A and B, it is assumed that annual investments in new reservoirs remain constant at the year 2000 value, the investment volume is assumed to be only half this size in the intervention variants. As in the reference scenarios, dam construction has priority in the scenario region with high potential water resources in scenario $\mathrm{B}$, and both in these regions and in the coastal region in scenario A. In Figure 10, the intervention scenarios are denoted by IS A-res and IS B-res, IS standing for Intervention Scenario and -res for reduced dam construction.

In the model simulations of IS A-res and B-res, stored water at the beginning of the dry season is less than in RS A and RS B (Fig. 11) for most years, illustrating the positive

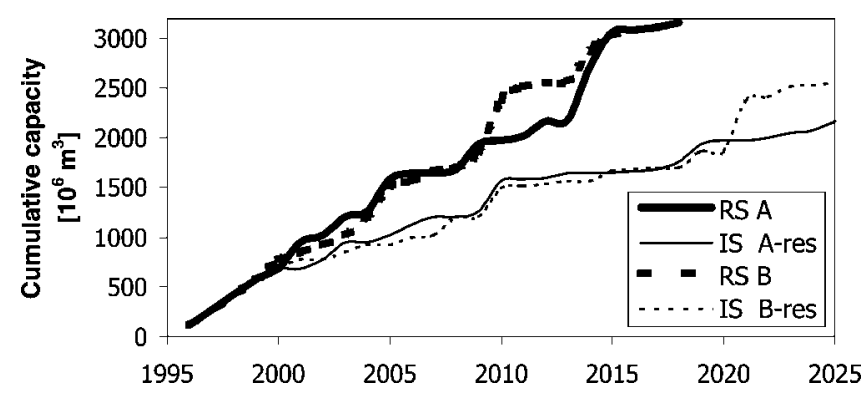

Fig. 10. Cumulative capacity of reservoirs constructed from 1996 to 2025, for reference and intervention scenarios. effect of newly installed water storage capacity on the availability of water. Note, however, that the differences in stored water volumes small compared to the differences in storage capacity (Fig. 10). In the dry years after 2010, the reduced reservoir construction in the intervention scenarios does not lead to a reduction of the volume of stored water. The relative filling of the new reservoirs at the start of the dry season is higher in the intervention scenarios (Fig. 12). This holds for both the scenarios A and B and indicates that the total installed storage capacity in the case of the interventions scenarios is nearing a level where the efficiency of new dams is highly reduced. The little added value of additional dam construction is due to the fact that the present dam density is so high that most of the runoff is being caught in reservoirs already today. New upstream reservoirs will store water but at the cost of storage downstream, and additional water storage is only achieved in wet years.

Reduced dam construction has only a very small impact on water scarcity. The smaller number of new reservoirs in IS A-res as compared to RS A lowers the mean sufficiency of water supply for irrigation between 2016 and 2025 from $80.5 \%$ to $80.1 \%$; for the B scenarios, the sufficiency declines from $88.0 \%$ to $87.8 \%$. The impact of climate change on the efficiency of water storage infrastructure and water sufficiency is not apparent until 2025 but is a potentially very significant process afterwards [5].

\subsection{Introduction of High-Yield Cashew Varieties}

Improved crop varieties, especially of cash crops, are being developed to increase yields and to support market orientation of the agricultural sector. In the intervention scenario "Cashew" it is assumed that the traditional cashew varieties are replaced by improved varieties with a four-fold yield potential from 2010 on. Prices for cashew nuts are assumed to remain stable. The potential benefit through the marketing of cashew fruits is not considered. The impact of this intervention is only assessed on the background of RS A.

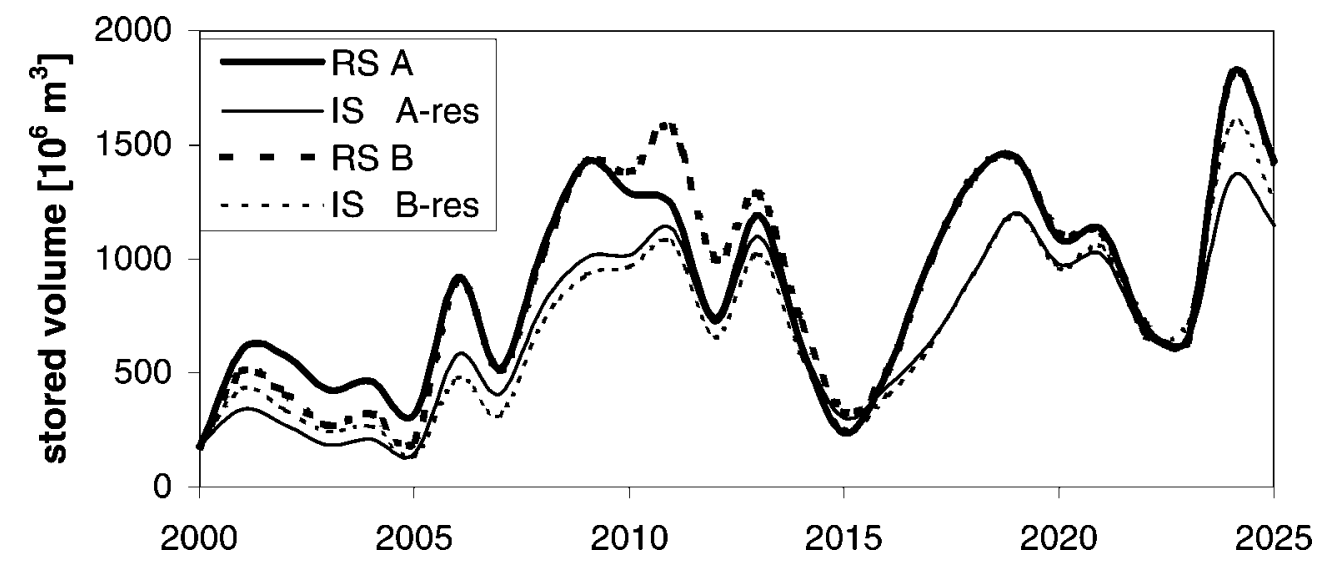

Fig. 11. Increase in stored water volume at the beginning of the dry season by reservoirs constructed after 1996 , for reference and intervention scenarios. 


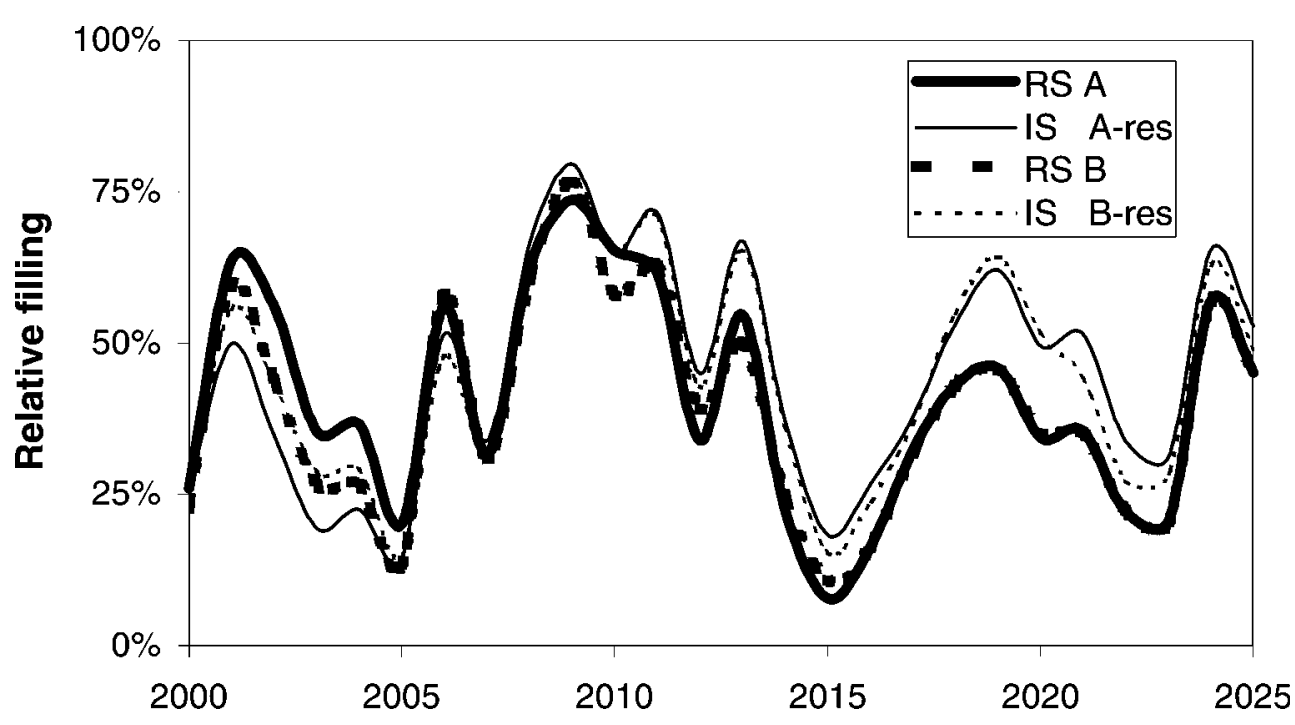

Fig. 12. Relative filling at the beginning of the dry season by reservoirs constructed after 1996, for reference and intervention scenarios.
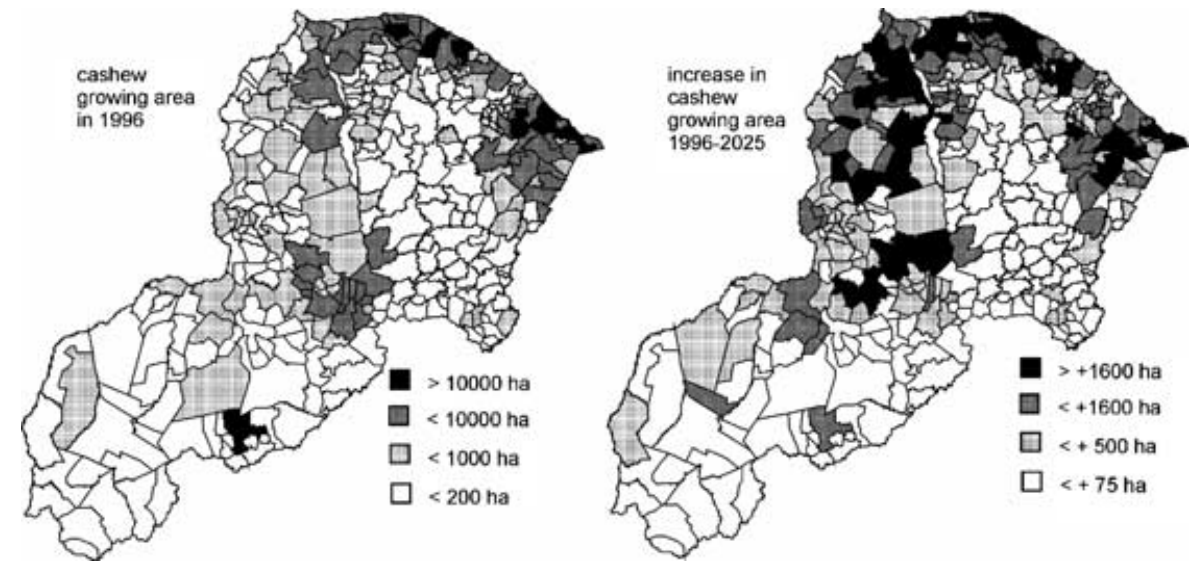

Fig. 13. Distribution of cashew cultivation in 1996 and change in cashew cultivating area as induced by the intervention, which results in a very significant productivity increase.

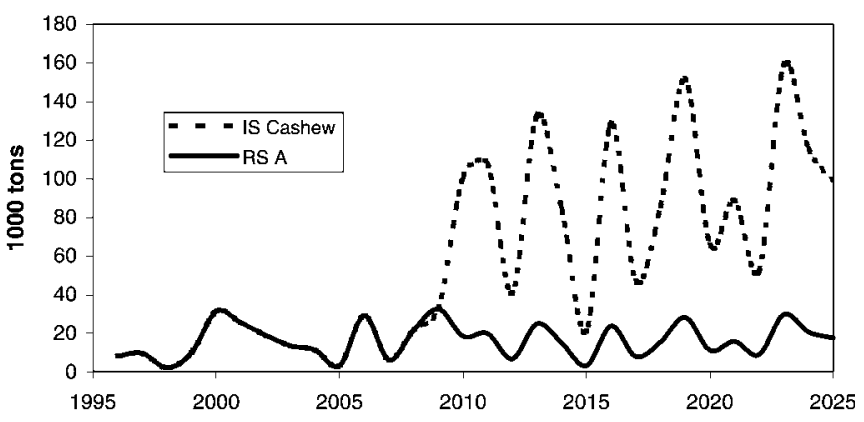

Fig. 14. Total production of cashew nuts in Ceará and Piauí in scenario A: reference scenario and intervention scenario "Cashew."

RASMO [7] computes the changes in agricultural land use resulting from the introduction of the high-yield cashew varieties. The cashew-growing area (both rain-fed and irrigated) increases by $44 \%$ (from 363 to $522 \cdot 10^{3}$ ha), especially in northern Piauí, the coastal municipalities and the lower part of the Jaguaribe catchment (Fig. 13). Cashew production increases by $440 \%$ (Fig. 14). The net effect on agricultural GDP amounts to about $+10 \%$ in the first decade after 2010 , lowering to about $8 \%$ to the end of the simulation period.

The projected net effect on migration is very small $(0.5 \%)$, partly because most migration-prone areas are simulated to benefit the least from the intervention due to restrictions by soil (clay and stony soils in the Sertão), climate and irrigation possibilities. The intervention would thus implicitly result in supporting regional development in the regions with competitive advantages (coastal zone and regions with large potential water resources).

\section{CONCLUSIONS AND RECOMMENDATIONS}

The developed integrated scenarios of regional development in Piauí and Ceará, in particular the model-based 
quantification of the system indicators related to water stress, agricultural production and migration lead to the following conclusions:

1. Water stress increases significantly only in case of the "Coastal Boom and Cash Crops" scenario, which is mainly due to the extension of irrigation (implementation of all currently planned public irrigation projects) and not caused by climate change.

2. If, in Ceará, the investments for new reservoirs do not continue until 2025 at the current rate but drop to only half the value, the volume of water which is stored in the new reservoirs at the beginning of the dry season will not be reduced much after 2010, and not at all in drought years. More importantly, water scarcity, expressed as the sufficiency of water supply to fulfil water demands, will not be significantly affected by the reduced dam construction.

3. Therefore, it is likely that the implementation of all currently planned irrigation projects would lead to low sufficiency of water supply for irrigation even if more reservoirs were constructed than assumed in the reference scenarios.

4. Due to the high price elasticity of domestic and industrial water demand, domestic and industrial water use can be efficiently managed by water price, in particular if all the industries were charged. (However, there is a lack of reliably data on price elasticities.) If the annual (inflationcorrected) water price increase is less than $6 \% / \mathrm{yr}$ (assumed in the reference scenarios), water stress will increase as domestic and industrial water demand will increase significantly. However, the impact of water price on the dominant water use sector, irrigation, could not be assessed.

5. In the "Coastal Boom and Cash Crops" scenario, the agricultural GDP increases more strongly than in the "Decentralisation - Integrated Rural Development" scenario which is due to higher production of irrigated crops. However, in both scenarios, inter-annual variability remains very high.

6. Assuming constant prices, introduction of high-productivity cashew varieties increases agricultural GDP by $8-$ $10 \%$.

7. Migration from the Sertão is somewhat less in the "Decentralisation - Integrated Rural Development" than in the "Coastal Boom and Cash Crops" scenario as regional income differences are smaller. In both scenarios, migration does not decrease significantly until 2025.

Please note that the uncertainty of the computed system indicators, and thus of the above conclusions, is high. The lack of knowledge about present-day irrigation, in particular about irrigated areas and multicropping, leads to significant uncertainty of the modelled water demand. Modelling of agricultural production and GDP suffers from a lack of reliable data on present-day cropping as well as coarse representation of price formation processes, credit availability, and informal marketing in the model. As to migration, only few of the reasons for migration that are well known qualitatively can be quantified, such that the impact of important drivers could not be included in the scenario development. A very important source of uncertainty is climate data, both historic data and climate change scenarios, which have a strong impact on computed water availability, irrigation water demand and crop productivity. For example, when the precipitation over Ceará is estimated based on about 200 measurement stations as compared to about 30 in the standard climate data set, 1969-1998 longterm average annual precipitation is estimated to be $844 \mathrm{~mm}$ instead of $924 \mathrm{~mm}$, which results in a $6 \%$ increase of computed irrigation water demand in Ceará. However, the conclusion concerning the modest impact of reduced investments for reservoir construction on alleviating water scarcity is quite robust with respect to different climate change scenarios. It holds for the climate change scenario with declining precipitation volumes (ECHAM4, applied in this paper), but also for constant or wetter climates. In a scenario with increasing precipitation (HadCM, see [5]), water scarcity decreases, but mainly due to irrigation demand decreases and the efficiency of present storage capacity; the relative inefficiency of additional storage capacity is found in this scenario, too.

What can be learnt from the experiences we made with developing integrated regional scenarios that were to support regional planning? Scenario development resulted in an improved interdisciplinary understanding and co-operation of those scientists that participated in the scenario group. It helped to combine a large amount of qualitative and quantitative knowledge in a transparent manner. The consistency of the derived scenarios was strongly supported by the application of models, and of the integrated model in particular. (In the presented scenarios, for example, the extension of irrigated crop production is restricted by water availability, while both variables are affected by climate change.) However, due to the large amount of model output, it was beyond the scope of the project to analyse the integrated results for all the sub-regions of the study area. The ability to quantify appropriate system indicators (for example for water scarcity) is decisive for a successful integration of scenarios into regional planning, but it is limited by the capabilities of the applied mathematical models, which again are often restricted by data availability.

The scenario development process is retarded when pertinent mathematical models do not already exist for the system components or the geographical area of interest. Even though it would seem ideal to start scenario development at the beginning of a project that is geared towards supporting regional planning, we found that policy makers, who should be involved in the scenario development, only became interested in co-operation after scientists could show the capabilities of their analytical tools as well as 
first scenario results. Even though regional planners (concerned with water resources and agriculture), in particular the minister of planning of Ceará, actively participated in the three policy workshops, the ministry was not willing to spend a moderate amount of money to enable the integration of the developed tools into the actual planning process. This may be related to the late involvement of the policy makers in the scenario development process (the policy workshops took place in the last year of the research project) but also to a political and administrative culture where most policy makers and technical experts change their jobs and responsibilities after each election and are thus not very interested in long-term efforts. One might conclude that scenario development can be policy-relevant only if it is the regional planners themselves and not the scientists who take the initiative.

To make scenarios relevant for regional planning, it is desirable to not only develop but also to evaluate them thoroughly, for example by a multi-criteria analysis. This should be done by a group consisting of researchers, policy makers and stakeholders, which may be the same as the scenario development group.

\section{ACKNOWLEDGEMENTS}

We acknowledge the important contributions of Dagmar Fuhr, Thomas Gaiser, Joachim Herfort, Sabine Höynck, Annekathrin Jaeger, Christoph Külls, E. Mario Mendiondo, Andreas Printz, Susanne Voerkelius, and José Carlos de Araújo in the development of the integrated scenarios. We thank the planning ministry (SEPLAN) and the water ministry (SRH) of Ceará for their interest in our work and for their co-operation in the policy workshops, CAGECE, AGESPISA, COGERH, CPRM and FUNCEME for supplying data and $\mathrm{BMBF}$ and $\mathrm{CNPq}$ for financial support.

\section{REFERENCES}

1. Nakicenovic, N. and Swart, R. (eds.): Emission Scenarios. IPCC Special Report on Emission Scenarios. Cambridge University Press, Cambridge, 2000.

2. Minx, E., Neuhaus, Ch. and Waschke, T.: Vom Brückenbauen oder: Wie machbar ist Interdisziplinarität? Organisationsentwicklung, Heft 1/93 (1993), pp. 52-64.

3. Cosgrove, W.J. and Rijsberman, F.R. (eds.): World Water Vision: Making Water Everybody's Business. Earthscan, London, 2000 (can be downloaded from http://www.worldwatercouncil.org/vision.shtml).

4. Alcamo, J.: Scenarios as Tools for International Environmental Assessments. Environmental Issue Report 24, European Environment Agency, Copenhagen, 2001.

5. Krol, M.S., Jaeger, A. and Bronstert, A.: Integrated Modelling of Climate Change Impacts in North-Eastern Brazil. In: T. Gaiser, M. Krol, H. Frischkorn and J.C. de Araújo (eds.): Global Change and Regional Impacts. Springer, Heidelberg, Berlin, 2003, pp. 43-56.

6. Döll, P. and Hauschild, M.: Model-Based Scenarios of Water Use in Two Semi-Arid Brazilian States. Regional Environmental Change 2(4), DOI 10.1007/s10113-002-0046-z, 2002, pp. 150-162.

7. Höynck, S.: Structure and Possible Development of the Agricultural Sector of Ceará and Piauí. In: T. Gaiser, M. Krol, H. Frischkorn and J.C. de Araújo (eds.): Global Change and Regional Impacts. Springer, Heidelberg, Berlin, 2003, pp. 375-388.

8. FAO: Irrigation in Latin America and the Caribbean in Figures. Water Reports 20, Rome, Italy, 2000.

9. Lopes Neto, A.: Possibilidades de Modernização Rural do Ceará através da Agricultura Irrigada e da Fruticultura. CNPq, SECITECE, Fortaleza, Brazil, 1998.

10. Gerstengarbe, F.-W. and Werner, P.C.: Climate Analysis and Scenarios for North-Eastern Brazil. In: T. Gaiser, M. Krol, H. Frischkorn and J.C. de Araújo (eds.): Global Change and Regional Impacts. Springer, Heidelberg, Berlin, 2003, pp. 137-151.

11. Güntner, A. and Bronstert, A.: Large-Scale Hydrological Modeling of a Semiarid Environment: Model Development, Validation and Application. In: T. Gaiser, M. Krol, H. Frischkorn and J.C. de Araújo (eds.): Global Change and Regional Impacts. Springer, Heidelberg, Berlin, 2003, pp. 217-228.

12. Fuhr, D.: Quality of Life and Migration - Concepts and Results of the Socio-Economic Survey in Tauá and Picos. In: T. Gaiser, M. Krol, H. Frischkorn and J.C. de Araújo (eds.): Global Change and Regional Impacts. Springer, Heidelberg, Berlin, 2003. 